\title{
Extracranial Repair of Cerebrospinal Fluid Rhinorrhea
}

\author{
Ian B. Ross, Austin R.T. Colohan and Martin J. Black
}

\begin{abstract}
There has been a recent renewal of interest in the extracranial repair of cerebrospinal fluid rhinorrhea because of the relatively high morbidity associated with the transcranial approach. The authors describe an extracranial approach that involves packing of the sphenoid and ethmoid sinuses on the side of the CSF leak. A case of successful treatment of CSF rhinorrhea by this method is presented. The extracranial approach may be advantageous for the repair of CSF rhinorrhea and the authors advocate an increase in its utilization by neurosurgeons and otolaryngologists working as a team.
\end{abstract}

RÉSUMÉ: Cure extracrânienne de la rhinorrhée cérébrospinale: une observation Il y a eu récemment un regain d'intérêt pour la cure extracrânienne de la rhinorrhée cérébrospinale à cause de la morbidité relativement élevée associée à l'approche transcrânienne. Les auteurs décrivent une approche extracrânienne qui implique le tamponnement des sinus sphénoïde et ethmoïde du côte de la fuite. Un cas de rhinorrhée cérébrospinale traité avec succès par cette méthode est présenté. L'approche extracrânienne peut être avantageuse pour la cure de la rhinorrhée cérébrospinale et les auteurs recommandent qu'elle soit pratiquée par une équipe formée d'un neurochirurgien et d'un otorhinolaryngologiste.

Can. J. Neurol. Sci. 1990; 17:320-323

The development of cerebrospinal fluid (CSF) rhinorrhea is a well known complication of head injury: but the investigation and treatment are controversial.

These leaks are often difficult to localize. 1.2,3 Post-traumatic rhinorrhea can occur from dural laceration and fracture in the frontal, ethmoid or sphenoid sinuses, or directly through the cribriform plate into the nose. Rarely, a temporal bone fracture into the mastoid sinus can lead to CSF rhinorrhea if the tympanic membrane is intact and the Eustacian tube is patent. ${ }^{4}$ Transcranial exploration and direct repair of the dural laceration has been advocated since Dandy's first successful repair of a traumatic dural laceration over a paranasal sinus in 1926.5 However, even at exploration, the site of the leak is not always found. Multiple explorations and attempts at repair have at times been necessary. ${ }^{2}$

A more indirect approach, by plugging or packing of the sinuses, was first proposed for the repair of intra- and post-operative leaks by Hirsch in 1952.6 Montgomery in 1963 helped to popularize this approach for leaks occurring after transphenoidal pituitary surgery. ${ }^{7}$ Both these reports were in the otolaryngology literature. Subsequently, otolaryngologists became interested in sinus packing for repair of post-traumatic fistulae. This became quite popular for a while, but intracranial complications, such as hematoma formation, gradually led to abandonment of the procedure. Interestingly, in 1969 Ray and Bergland advocated packing of the sphenoid sinus via a transcranial approach when exploration failed to reveal the site of the fistula causing rhinorrhea. ${ }^{3}$ Neurosurgical interest in the extracranial packing of sinuses for CSF leaks was revived when Persky et al presented a paper at the 1988 American Association of Neurological Surgeons Annual Meeting. 8 They reported an $86 \%$ success rate in treating cerebrospinal fluid leaks with selective packing of the sinuses. A $100 \%$ success rate using similar methods was reported by Calcaterra in $1980 .{ }^{9}$

We report here a patient with post-traumatic CSF rhinorrhea treated by packing of the ethmoid and sphenoid sinuses, and describe the technique utilized.

\section{TEChNIQUe}

The approach to the ethmoid and sphenoid sinuses is nicely described and illustrated elsewhere. ${ }^{10}$ However, a brief description of the entire procedure is given here.

The operation is done in association with an otolaryngologist. An incision is made just inferior to the eyebrow and carried medially and then inferiorly onto the base of the nose. After the lacrimal sac and orbital contents are dissected free and retracted laterally (Figure 1), the anterior ethmoid air cells are entered through the lamina papyracea. The ethmoid sinus cells are cleared of mucosa and the anterior wall of the sphenoid sinus is

From the Departments of Neurology and Neurosurgery (I.B.R., A.R.T.C.) and Otolaryngology (M.J.B.), Sir Mortimer B. Davis - Jewish General Hospital, McGill University, Montreal

Recieved February 21, 1990. Accepted April 2, 1990

Reprint requests to: Austin R.T. Colohan, M.D. The Emory Clinic, Division of Neurosurgery, 1365 Clifton Road, N.E., Atlanta, Georgia 30322 U.S.A. 
identified. The image itensifier can be used to confirm the anatomy at this point. The sphenoid sinus is then entered and its mucosa is cleared. The operating microscope provides good illumination and visualization (Figure 2). A lumbar drain can be inserted at the start of the procedure and the CSF pressure raised to help visualize the site of the leak, though this is not always successful. Intrathecal administration of fluorescein is sometimes helpful. After all of the mucosa has been removed from the sphenoid sinus, the ethmoid and sphenoid sinuses are packed with muscle, fat and fascia harvested from the lateral thigh. The orbital contents are then allowed to fall back into place. The medial canthal ligament is reapproximated to periosteum with absorbable suture and the skin is then closed with fine interrupted nylon sutures.

The procedure is well tolerated by the patient, with a shorter post operative recovery than after craniotomy. The high incidence of anosmia frequently seen in the transcranial approach is also avoided.

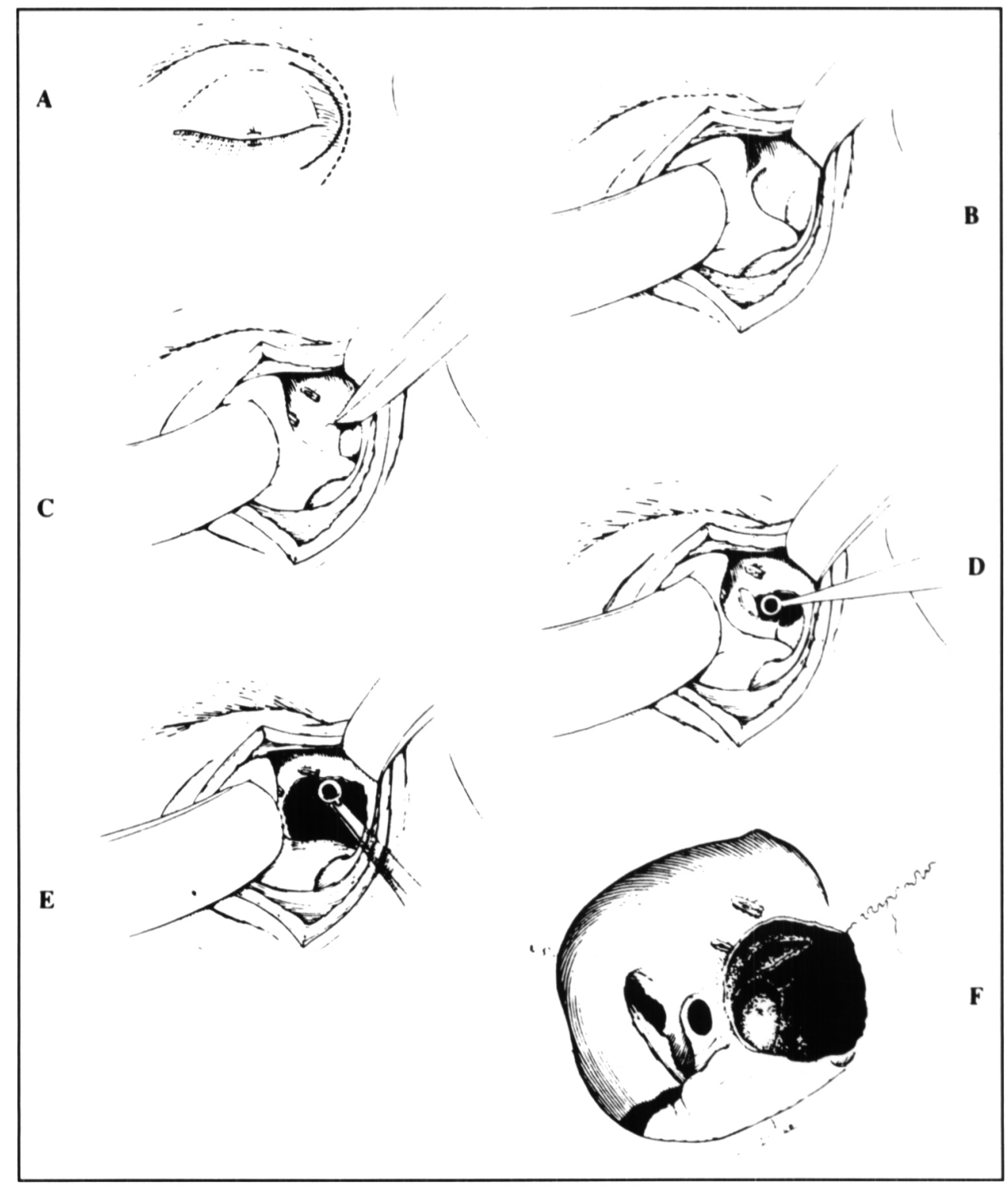

Figure I - Right medial orbital approach toward the ethmoid air cells and sphenoid sinus.

A. After the face has been cleaned and draped, incision is made inferior to the eyebrow' (dark line).

B. Orbital contents are retracted laterally. The rrochlea of the superior oblique muscle limits the exposure superiorly and the lacrimal sac limits the exposure inferiorly.

C. The anterior and posterior ethmoidal arteries have been clipped and divided. Ethmoidectomy is started by opening the cell just inferior to the anterior ethmoidal artery.

D. The opening is enlarged.

$\boldsymbol{E}, \boldsymbol{F}$. Further dissection exposes all the air cells on this side. The sphenoid sinus is then opened and cleared of mucosa. (From Ritter SN. The paranasal sinuses; anatomy and surgical technique, ed. 2. The C.V. Mosby Company, St. Louis, 1978.) 


\section{CASE REPORT}

This 59 year old female had suffered multiple injuries in a motor vehicle accident. Among these injuries, there had been a clinically diagnosed basal skull fracture, and also a left temporo-parietal hematoma that required surgical evacuation. She presented with a 10 month history of rhinorrhea from the right nostril. This started 6 months post-injury and had been continuous since that time. A metrizamide cisternogram was unsuccessful in locating the source of the leak. She underwent a lumbar peritoneal shunting procedure. This decreased, but did not stop, the flow. The patient was readmitted three months later. A CSF isotope study at that time indicated the greatest amount of activity to be coming from the right superior meatus. She underwent a right ethmoidectomysphenoidectomy and packing of these sinuses with muscle-fat-fascia. There was no evidence of rhinorrhea at follow-up ten months later.

\section{Discussion}

The complications of transcranial surgery in the repair of dural fistulae and CSF leaks are well known. 1.2 Extracranial sinus surgery for repair of CSF leaks avoids these problems, and thus seems preferable. The report by Persky et al describes selective procedures on the frontal, ethmoid, sphenoid, and mastoid sinuses. ${ }^{8}$ With direct or indirect evidence localizing the side of the fistula to the ethmoid or sphenoid sinuses, we agree that the extracranial approach for packing of these sinuses is a safe and

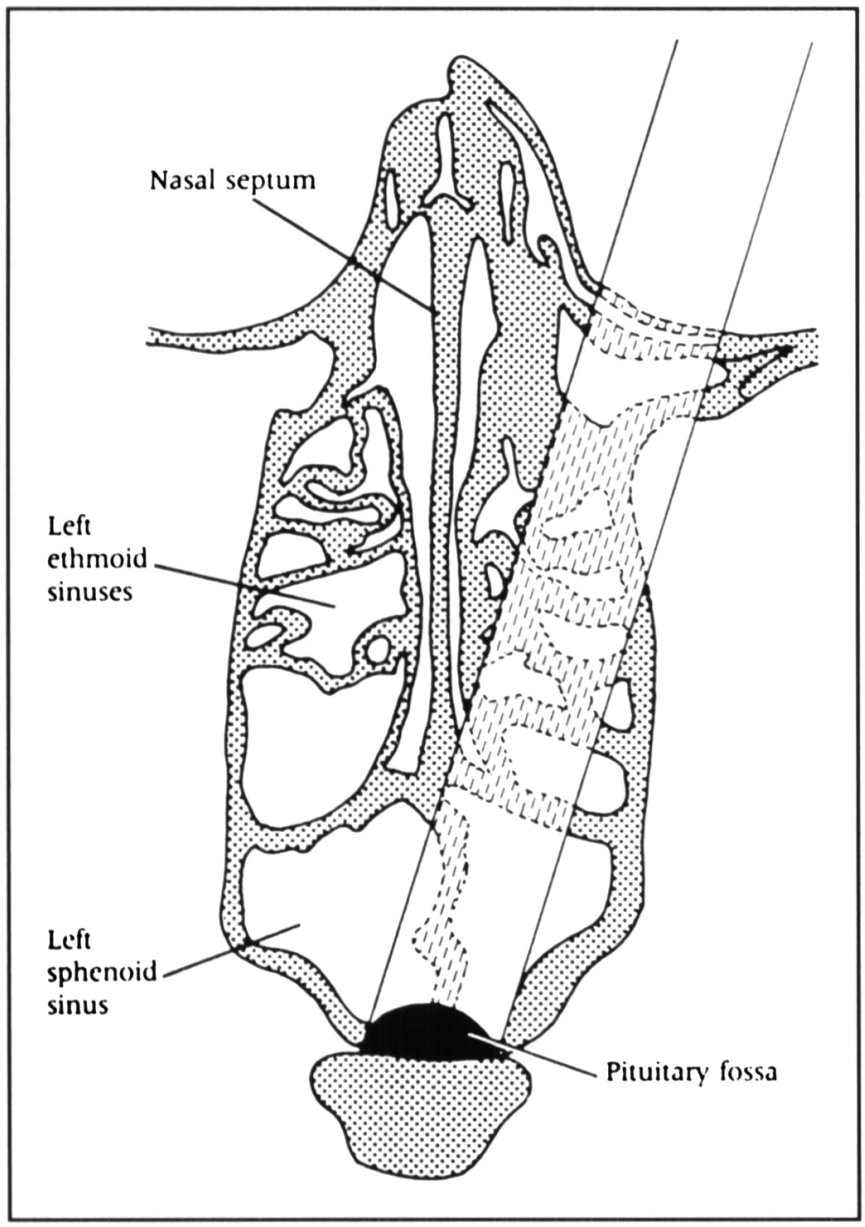

Figure 2 - Operative approach diagrammatically viewed from above. (From Sasaki CT. Pituitary ablation for carcinoma of the breast: Transethmoidal approach to the sella. Otolaryngol Clin North Am, 1981: 14:391-403.) effective alternative to intracranial exploration and direct dural repair.

In cases of CSF rhinorrhea, the usual communications between the nose and the intracranial cavity are through the frontal, ethmoid or sphenoid sinuses, or through the cribriform plate (Figure 3). Fractures of the frontal bone, or other parts of the anterior fossa can cause tears in the adjacent dura and allow for free flow of cerebrospinal fluid into the nose. A number of techniques are used to localize these fistulae. Standard skull films, special views of the anterior fossa"l and computed tomography may show defects in the bone or opacification of the sinuses. Metrizamide studies and radionuclide studies with nasal pledgets can also help to locate the site of the leak.12

Unfortunately, in our experience, these techniques are often not helpful. It is quite often impossible to pinpoint the site of the dural fistula pre-operatively or even to identify it at the time of bifrontal craniotomy. Clinically, the side of the rhinorrhea usually correctly lateralizes the defect. ${ }^{13}$

Because the exact location of a traumatic fistula is often not determined pre-operatively, knowledge of fracture patterns is needed to help infer its site. The cribriform plate is not usually the site of a fistula. ${ }^{2}$ Fractures tend to run around the cribriform plate. Johnson and Dutt studied over 80 traumatic dural lacera-

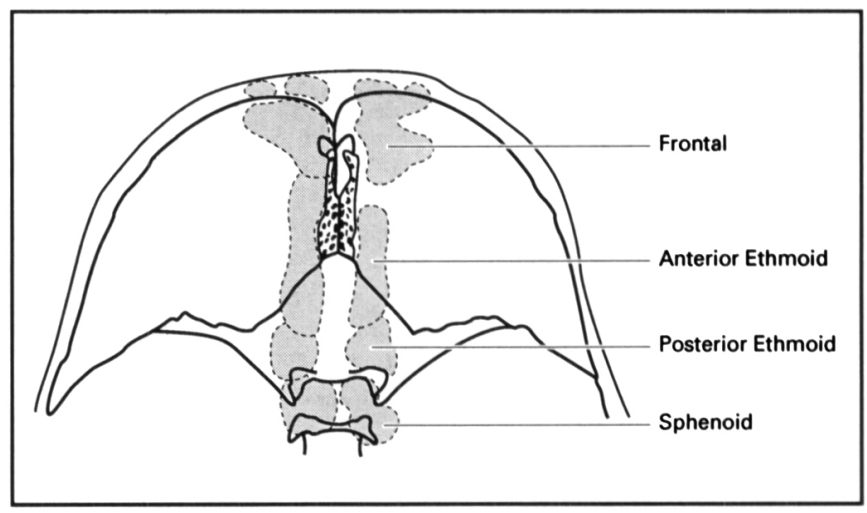

Figure 3 - Paranasal sinuses. Approximate positions as viewed from above.

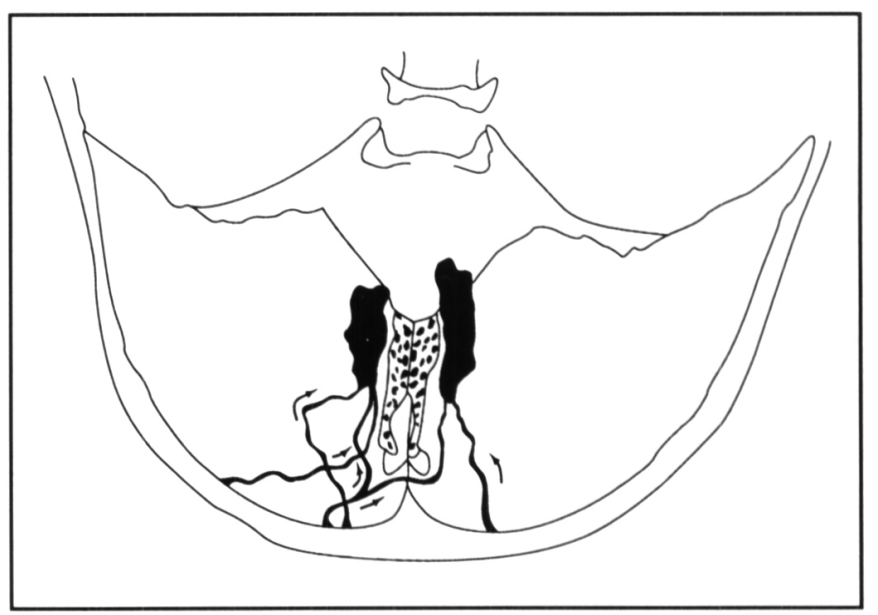

Figure 4 - Anterior fossa fracture patterns. (Adapted from Johnson $R T$, Dutt $P$. On dural laceration over paranasal and petrous air sinuses. Br J Surg. War Surg Suppl 1947; 1:141-167.) 
tions. 11 The anterior fossa fracture patterns seen tended to avoid areas of thicker bone, specifically the cribriform plate and the orbital roof (Figure 4). They noted that frontal fractures that run into the anterior fossa and then "disappear" on the radiographs often involve the ethmoid sinuses; and that this sinus is often the site of the fistula. 2,11

For these reasons, we believe that packing of the ethmoid and sphenoid sinuses on the side of the leak is a good alternative surgical treatment of cerebrospinal fluid rhinorrhea, if the site of the fistula is not localized. It should also be a good procedure if a fistula into either of these sinuses has been confirmed. If there is a strong suspicion that the frontal sinus is also involved, it can be packed at the same time. If the cribriform plate is thought to be involved, both the ethmoid roof and the cribriform plate can be covered using a posteriorly based mucoperiosteal flap, as described by Montgomery. ${ }^{14}$ Leaks through the sphenoid sinus are much less common than through the ethmoid sinus; ${ }^{2}$ but packing of the sphenoid sinus does not involve greater risk or morbidity. Thus we feel it should be part of the procedure if the fistula has not been localized. In the case presented, muscle, fat and fascia were used to pack the sinuses. It is not certain whether all of these components are necessary. It is our general impression that fat remains more viable than either muscle or facia. Various fibrin glues might add a component of security.

Both an otolaryngologist and a neurosurgeon should be involved in this extracranial procedure for the repair of cerebrospinal fluid rhinorrhea. Otolaryngologists are more familiar with this approach to the sinuses. Neurosurgeons have a greater understanding of the underlying pathophysiology.

In summary, we believe that extracranial packing of the ethmoid and sphenoid sinuses is an effective alternative method for the repair of properly selected cases of cerebrospinal fluid rhinorrhea and should be more frequently discussed in the neurosurgical literature.

\section{ACKNOWLEDGEMENT}

The authors wish to thank Ms. Gloria Gillespie for preparing the manuscript.

\section{REFERENCES}

1. Ommaya AK. Cerebrospinal fluid fistula. In: Wilkins RH, Rengachary SS, eds. Neurosurgery. New York: McGraw-Hill $1985 ; 1637-45$.

2. Morley TP, Hetherington RF. Traumatic cerebrospinal fluid rhinorrhea and otorrhea, pneumocephalus, and meningitis. Surg Gynecol Obstet 1957; 104: 88-98.

3. Ray BS, Bergland RM. Cerebrospinal fluid fistula: Clinical aspects, techniques of localization and methods of closure. $J$ Neurosurg 1969; 30: 399-405.

4. Henry RC, Taylor PH. Cerebrospinal fluid otorrhea and otorhinorrhea following closed head injury. J Laryngol Otol 1978; 92 : 743-755.

5. Dandy WE. Pneumocephalus (intracranial pneumotocele or aerocele). Arch Surg 1926; 12: 949-882.

6. Hirsch O. Successful closure of cerebrospinal fluid rhinorrhea by endonasal surgery. AMA Arch Otolaryngol 1952; 56: 1-12.

7. Montgomery WW. Transethmoidosphenoidal hypophysectomy with septal mucosal flap. Arch Otolaryngol 1963; 78: 68-77.

8. Persky MS, Cooper PR, Ransohoff J. et al. Extracranial repair of cerebrospinal fluid rhinorrhea and otorrhea. Scientific Program, American Association of Neurological Surgeons Annual Meeting 1988; 224.

9. Calcaterrra TC. Extracranial surgical repair of cerebrospinal rhinorrhea. Ann Otol 1980; 108-116.

10. Sasaki CT, McCabe BF, Kirchner JA. Surgery of the skull base. J.B. Lippincott Company, Philadelphia 1984; 63-78.

11. Johnson RT, Dutt P. On dural laceration over paranasal and petrous air sinuses. Br J Surg, War Suppl 1947; 1: 141-167.

12. Spetzler RF, Wilson CB. Dural fistulae and their repair. $I n$ : Youmans JR, ed. Neurological Surgery, ed. 2. Philadelphia W.B. Saunders Company 1982; 2209-2227.

13. Lewin W. Cerebrospinal fluid rhinorrhea in closed head injuries. Br J Surg 1954; 42: 1-18.

14. Montgomery WW. Cerebrospinal fluid rhinorrhea. Otoloaryngol Clin North Am 1973; 6: 757-771. 